\title{
EDITORIAL
}

\section{Making the diagnosis of gastrointestinal GVHD: is evaluation of the ileum necessary?}

\author{
Bone Marrow Transplantation (2012) 47, 321-322; \\ doi:10.1038/bmt.2011.157
}

GVHD remains the primary source of morbidity and mortality following allo SCT, although the more severe forms of the disease are becoming less frequent. ${ }^{1,2}$ Acute GVHD manifests primarily as skin, gut and liver disease with the gastrointestinal tract (GI tract) being the most commonly affected visceral organ. ${ }^{3}$ A clinical diagnosis of GI GVHD is frequently confirmed by finding apoptosis on mucosal biopsy. The site within the GI tract where biopsy is most likely to be diagnostic remains a topic of debate with various retrospective reviews advocating stomach, duodenum and rectosigmoid as having the highest yield. ${ }^{4-6}$ The provocative article by Kreisel et ll $^{7}$ appearing in this issue of the journal adds to this debate by advocating evaluation of the terminal ileum. In their retrospective study, the authors found macroscopic endoscopic findings correlated with histological evidence for GVHD. In addition, they found that ileal biopsies were more likely to make the diagnosis then biopsy from other sites.

The aim of the authors was to retrospectively determine the predictive value of endoscopically identified mucosal abnormalities in patients who had histologically confirmed acute GVHD of the GI tract. Patients who had histologic grade 1 GVHD were removed from their analysis because 'immunosuppressive therapy is not changed based on its presence'. Removal of these patients is fundamentally flawed. First and foremost, there is no support in the literature for making GVHD treatment decisions based on the histologic grade of acute GVHD, which has been shown to correlate poorly with clinical severity. ${ }^{8}$ Suggesting that patients who have histologic grade 1 GI GVHD do not require treatment does not reflect current clinical practice. ${ }^{9}$ It may be possible that the authors are confusing histological grading with clinical grading of acute GVHD where it is often standard practice to not intensify therapy for patients with overall clinical grade 1 acute GVHD ( $<50 \%$ skin rash). By definition, all patients with visceral organ involvement have a minimum clinical grade 2 GVHD for which initiation of systemic steroids is standard practice.

In fact, histologic grade 1 GI GVHD (apoptosis) is the most common finding for patients with GI GVHD being present in $90 \%$ of patients with acute GVHD of the lower GI tract as compared with only $11-14 \%$ of negative controls. $^{10-12}$ In comparison, grade 2 (crypt abscess) is routinely identified in only $2 \%$ of patients and grade III and IV (crypt drop out) only occurring in 30\% of patients. Previous studies have shown that the histologic grade correlates poorly with patient's clinical grade, response to therapy and survival outcomes. The sole exception is patients with histologic grade 4 acute GVHD who have more severe clinical manifestations and a poor prognosis. ${ }^{13}$ Therefore, removal of histological grade 1 patients from the analysis removes a large fraction of patients with clinically significant GVHD and raises the question if the author's findings are applicable to the typical patient referred for endoscopy. It is likely that removal of these patients from their analysis overrepresented the frequency in which endoscopic abnormalities were identified in patients suspected of having GVHD. Because one does not know the histologic grade before performing the procedure, it would seem impossible to determine in advance who would benefit most from endoscopic examination of the ileum. The authors' arbitrary decision to ignore grade I histological disease flies in the face of the general trend to make the diagnosis based on increasingly more subtle findings. ${ }^{9}$ So, if grade 1 histological disease is included, then gastroscopy plus rectosigmoid biopsies actually outperform colonoscopy with ileal biopsies in terms of diagnostic accuracy, 93 vs $87 \%$, as shown in Table 5 of the report.

Kriesel and colleague's findings conflict with other reports, which found mild to no abnormalities on endoscopy in the majority of patients being evaluated for possible GI GVHD. ${ }^{4,5}$ In addition, reports from centers that routinely undertake endoscopic evaluation of the terminal ileum do not consistently find a high prevalence of abnormalities in the area. ${ }^{14}$ It is likely the authors' results may reflect a more advanced or chronic version of gut GVHD in light of the relatively long interval between transplant and endoscopy compared with other studies. Other reports do find correlation between endoscopic appearance in grade III and IV GVHD, but not milder forms. ${ }^{15}$ However, in light of the adverse effect on mortality with more advanced GVHD, the usual practice is to make the diagnosis as early in the disease process as possible. Response to initial therapy with steroids is dependent upon prompt initiation of therapy. Response to initial therapy is vital as second-line therapies are of limited benefit. If GVHD is allowed to progress to a more advanced grade then response to high-dose steroids is diminished. ${ }^{16}$

That the ileum would have macroscopic findings in advanced cases is not surprising as early autopsy data demonstrated a predilection for GI GHVD to involve the ileocecal area. ${ }^{17}$ However, access to this area is more problematic than performing a gastroscopy or flexible sigmoidoscopy. So, the relevant question is whether the additional information from ileal evaluation is worth the extra effort required. It is unclear from the report what kind of preparation, if any, was necessary to perform 
colonoscopy. To ask critically ill inpatients to go through a colonoscopy prep has to have a robust rationale.

If endoscopic ileal assessment was felt to be essential, a viable alternative is wireless capsule endoscopy to document the presence of macroscopic disease. Preliminary reports of this technology in the setting of acute GVHD are inconsistent as to the predominance of mucosal findings in the terminal ileum. ${ }^{18,19}$ Abdominal computerized tomography in the setting of acute GVHD also fails to demonstrate selective ileal involvement as the most common pattern seen is diffuse involvement of both large and small intestine in $86 \%$ of patients. ${ }^{20}$

So, although provocative, the report by Kreisel et al. provides insufficient reasons to alter our current practice of emphasizing rectosigmoid biopsies. ${ }^{5}$ In a patient with clinical course strongly suggestive of GI GVHD but negative biopsies in the upper gut and rectosigmoid, colonoscopy with ileal intubation could be considered to pathologically confirm the disease. However, to adopt such measures as routine practice the evidence will have to be more compelling.

\section{Conflict of interest}

The authors declare no conflict of interest.

WA Ross ${ }^{1}$ and AM Alousi ${ }^{2}$
${ }^{1}$ Departments of Gastroenterology, Hepatology and
Nutrition, MD Anderson Cancer Center,
Houston, TX, USA and
${ }^{2}$ Department of Stem Cell Transplantation, MD Anderson
Cancer Center, Houston, TX,USA
E-mail: wross@mdanderson.org

\section{References}

1 Ferrara JL, Levine JE, Reddy P, Holler E. Graft-versus-host disease. Lancet 2009; 373: 1550-1561.

2 Gooley TA, Chien JW, Pergam SA, Hingorani S, Sorror ML, Boeckh M et al. Reduced mortality after allogeneic hematopoietic-cell transplantation. $N$ Engl $J$ Med 2010; 363: 2091-2101.

3 Martin PJ, McDonald GB, Sanders JE, Anasetti C, Appelbaum FR, Deeg HJ et al. Increasingly frequent diagnosis of acute gastrointestinal graft-versus-host disease after allogeneic hematopoietic cell transplantation. Biol Blood Marrow Transplant 2004; 10: 320-327.

4 Ponec RJ, Hackman RC, McDonald GB. Endoscopic and histologic diagnosis of intestinal graft-versus-host disease after marrow transplantation. Gastrointest Endosc 1999; 49: 612-621.

5 Ross WA, Ghosh S, Dekovich AA, Liu S, Ayers GD, Cleary KR et al. Endoscopic biopsy diagnosis of acute gastrointestinal graft-versus-host disease: rectosigmoid biopsies are more sensitive than upper gastrointestinal biopsies. Am J Gastroenterol 2008; 103: 982-989.

6 Socie G, Mary JY, Lemann M, Daneshpouy M, Guardiola P, Meignin V et al. Prognostic value of apoptotic cells and infiltrating neutrophils in graft-versus-host disease of the gastrointestinal tract in humans: TNF and Fas expression. Blood 2004; 103: 50-57.

7 Kreisel W. Endoscopic diagnosis of acute intestinal graftversus-host disease following allogeneic hematopoietic stem cell transplantation: a retrospective analysis in 175 patients. Bone Marrow Transplant 2012; 47: 430-438.

8 Massi D, Fondi C, Nozzoli C, Benemei S, Lapi F, Albarello L et al. The impact of histopathologic examination of graftversus-host disease in the era of reduced-intensity conditioning regimen: a study from the Gruppo Italiano Trapianto di Midollo Osseo. Hum Pathol 2011; 42: 254-268.

9 Washington K, Jagasia M. Pathology of graft-versus-host disease in the gastrointestinal tract. Hum Pathol 2009; 40: 909-917.

10 Epstein RJ, McDonald GB, Sale GE, Shulman HM, Thomas ED. The diagnostic accuracy of the rectal biopsy in acute graft-versus-host disease: a prospective study of thirteen patients. Gastroenterology 1980; 78: 764-771.

11 Nguyen CV, Kastenberg DM, Choudhary C, Katz LC, DiMarino A, Palazzo JP. Is single-cell apoptosis sufficient for the diagnosis of graft-versus-host disease in the colon? Dig Dis Sci 2008; 53: 747-756.

12 Shidham VB, Chang CC, Shidham G, Ghazala F, Lindholm PF, Kampalath B et al. Colon biopsies for evaluation of acute graft-versus-host disease (A-GVHD) in allogeneic bone marrow transplant patients. BMC Gastroenterol 2003; 3 : 5 .

13 Melson J, Jakate S, Fung H, Arai S, Keshavarzian A. Crypt loss is a marker of clinical severity of acute gastrointestinal graft-versus-host disease. Am J Hematol 2007; 82: 881-886.

14 He JD, Liu YL, Wang ZF, Liu DH, Chen H, Chen YH. Colonoscopy in the diagnosis of intestinal graft versus host disease and cytomegalovirus enteritis following allogeneic haematopoietic stem cell transplantation. Chin Med J (Engl) 2008; 121: 1285-1289.

15 Cheung DY, Kim JI, Kim SS, Sung HY, Cho SH, Park SH et al. Endoscopic evaluation in gastrointestinal graft-versushost disease: comparisons with histological findings. Dig Dis Sci 2008; 53: 2947-2954.

16 MacMillan ML, Weisdorf DJ, Wagner JE, DeFor TE, Burns LJ, Ramsay NK et al. Response of 443 patients to steroids as primary therapy for acute graft-versus-host disease: comparison of grading systems. Biol Blood Marrow Transplant 2002; 8: 387-394.

17 Spencer GD, Shulman HM, Myerson D, Thomas ED, McDonald GB. Diffuse intestinal ulceration after marrow transplantation: a clinicopathologic study of 13 patients. Hum Pathol 1986; 17: 621-633.

18 Neumann S, Schoppmeyer K, Lange T, Wiedmann M, Golsong J, Tannapfel A et al. Wireless capsule endoscopy for diagnosis of acute intestinal graft-versus-host disease. Gastrointest Endosc 2007; 65: 403-409.

19 Varadarajan P, Dunford LM, Thomas JA, Brown K, Paplham $\mathrm{P}$, Syta M et al. Seeing what's out of sight: wireless capsule endoscopy's unique ability to visualize and accurately assess the severity of gastrointestinal graft-versus-host-disease. Biol Blood Marrow Transplant 2009; 15: 643-648.

20 Brodoefel H, Bethge W, Vogel M, Fenchel M, Faul C, Wehrmann $\mathrm{M}$ et al. Early and late-onset acute GvHD following hematopoietic cell transplantation: CT features of gastrointestinal involvement with clinical and pathological correlation. Eur J Radiol 73: 594-600. 